\title{
"Ser alguém na vida": uma análise sócio-antropológica da gravidez/maternidade na adolescência, em Belém do Pará, Brasil
}

\author{
"Be someone in life": a socio-anthropological \\ analysis of adolescent pregnancy and motherhood \\ in Belém, Pará State, Brazil
}

\footnotetext{
${ }^{1}$ Núcleo de Altos Estudos Amazônicos, Universidade Federal do Pará. Rua Augusto Corrêa 1, Belém, PA 66075-900, Brasil. anauar@zipmail.com.br
}

\begin{abstract}
Focused on a group of low-income youth in Belém, Pará State, Brazil, this study discusses the issue of adolescent pregnancy and motherhood from a socio-anthropological perspective. Aimed at an understanding of the cultural meanings of this event in this context, the study suggests that for adolescent girls, it does not mean a break with life projects. On the contrary, pregnancy and motherhood are valued to the extent that they produce changes in social status for the girls, in terms of affirmation of projects for social mobility in the future, thus justifying the continuity of studies in the face of difficulties imposed by the situation.

Key words Adolescent; Pregnancy in Adolescence; Sexuality; Gender Relations

Resumo Tendo como universo de análise um grupo de jovens de camadas populares de Belém do Pará, este estudo traz para debate a questão da gravidez/maternidade na adolescência com base em uma perspectiva sócio-antropológica. Objetivando uma compreensão dos significados culturais do evento nesse contexto, o estudo aponta que o mesmo não implica, para as meninas, a ruptura ou abandono de projetos de vida. Ao contrário, a gravidez/maternidade é valorizada por traduzir tanto mudanças de status social para as mesmas, quanto a afirmação de projetos de mobilidade social no futuro, justificando assim, a continuidade dos estudos diante das dificuldades que a situação impõe.

Palavras-chave Adolescente; Gravidez na Adolescência; Sexualidade; Relações entre Gênero
\end{abstract}




\section{Introdução}

As estatísticas apresentadas por demógrafos e estudiosos da área da saúde pública têm enfatizado, com freqüência, o significativo aumento do número de adolescentes grávidas nas últimas décadas. Tema de intensos debates na esfera da saúde reprodutiva, a gravidez na adolescência também tem sido popularizada pelos meios de comunicação, o que em muito tem contribuído para sua maior visibilidade social. Esta, no entanto, tem se pautado em um discurso vitimizador, homogeneizador e alarmista da questão, no qual o evento assume um caráter negativo, instaurador de mudanças radicais na vida das adolescentes e de suas famílias, sendo o abandono dos estudos referido como um dos seus principais prejuízos.

\section{Objetivos}

Este estudo traz uma proposta alternativa a essa visão, tendo por base a investigação acerca da lógica social/cultural subjacente ao fenômeno para estudantes na faixa etária entre $13 \mathrm{e}$ 18 anos em Belém do Pará. Objetiva-se uma compreensão dos significados socioculturais do evento nesse universo, uma vez que para além daquilo que é normatizado como fracasso, sob outro olhar, pode estar implícita a concretização de um sonho (Hernández, 2001, apud Costa, 2002), ou a realização de projetos de vida e, portanto, como sucesso. Adotar essa perspectiva implica o reconhecimento de uma abordagem em que o evento possa ser visto/estudado senão como parte importante, pelo menos como possibilidade a ser considerada dentro das experiências que definem o processo de transição juvenil (M. Bozon, comunicação pessoal), para além, portanto, da noção de "risco", "queda" ou "ruptura" freqüentemente associada ao mesmo.

Gravidez na adolescência: a (des)construção do problema

Apesar de o fenômeno da gravidez na adolescência não ser novidade no Brasil, foi somente há algumas décadas que o mesmo foi tomado como um "problema social", inserido em um quadro de "gravidade" e "risco" que passou a demandar a tomada de ações efetivas. Essa noção sobressai no contexto de um aumento significativo do número de partos realizados em hospitais, contribuindo para que, tanto no Brasil como em outros países, a questão do risco médico fosse evidenciada (M. Bozon, comuni- cação pessoal). Difundido amplamente, o discurso médico passou inclusive a ser utilizado entre jornalistas, políticos e demógrafos.

O risco relacionado ao aborto assume destaque nesse discurso estando associado à idéia de rejeição à gravidez pela adolescente, desconsiderando-se que tal prática é também freqüente entre mulheres acima de 19 anos. O risco durante o parto - apontado pela medicina e reiterado pela saúde pública - estaria relacionado à suposta imaturidade anátomo-fisiológica, da qual decorreriam outros problemas de saúde como uma maior incidência de baixo peso da criança ao nascer e/ou prematuridade (Camarano, 1998; Carneiro \& Matos, 1999; Rees et al., 1997). Recente estudo antropológico, no entanto, sugere outras possibilidades de interpretação, apontando o quanto tomar a idade da mãe como fator isolado para analisar os indicadores materno-infantis pode implicar uma visão reducionista do fenômeno. Com base nos indicadores de mortalidade perinatal, baixo peso ao nascer (BPN) e prematuridade, Costa (2002) defende ser entre os filhos de mulheres na faixa de 10 a 14 anos que o risco recai com maior ênfase e não entre todas as mães adolescentes.

No âmbito da psicologia tradicional, o discurso do risco psicossocial - cujo diagnóstico seria a imaturidade psicológica dos jovens -, adquire ênfase. Vista como precoce, a gravidez nessa ótica emerge como causa de problemas psíquicos e sociais vários para as adolescentes e seus filhos. Ao resvalar para o campo da moral, senão até para o moralismo, esse discurso assume "uma oscilação que vai da condenação e o apelo ao apoio moral aos adolescentes" (M. Bozon, comunicação pessoal).

Na esfera da saúde publica, persiste o discurso normativo que considera o evento um fator de risco social (Carneiro, 1998; MS, 1996, 1997). Nessa visão, a gravidez resultaria da pobreza, da precariedade e da falta de acesso aos serviços de saúde, portanto, é considerada como um reforço à pobreza e marginalidade. Uma vez indesejada, a gravidez acarretaria prejuízos para as adolescentes como, abandono dos estudos, dificuldade em encontrar emprego, contando as mesmas apenas com uma ajuda limitada da família.

Interpretações de natureza causal têm implicado uma visão reducionista do fenômeno, pois, muito embora a gravidez na adolescência encontre-se com freqüência relacionada a um contexto de desvantagem social das garotas, é preciso considerar que sua ocorrência já se dá num âmbito pontuado por oportunidades restritas, poucas opções de vida e marcado por interrupções na trajetória escolar (Stern \& Gar- 
cia, 1999). Em cenários como esse, inclusive, a maternidade pode adquirir centralidade, impondo-se muitas vezes, como uma (entre poucas) alternativa de vida para as adolescentes. Esse argumento tem por base o pressuposto também equivocado de que a adolescência é uma etapa universal do desenvolvimento humano, sendo o adolescente visto a partir de características supostamente generalizáveis para todos eles (Stern \& Garcia, 1999). Ao privilegiar o fator idade como elemento fundamental de análise, esses estudos desconsideram as diferenças sociais que marcam de forma distinta as etapas da vida humana e as múltiplas e variadas implicações que o evento produz sobre as trajetórias das meninas e suas redes familiares. Ademais, a utilização do critério etário na definição da adolescência, tende a obscurecer a assimetria nas relações de gênero e as possibilidades concretas e distintas de "escolha" para as garotas das diferentes camadas sociais.

Nesse sentido, há que se ter cuidado para não incorrer em generalizações, pois, ao se conceituar a adolescência enquanto uma fase que também é social/cultural e por isso mesmo repleta de singularidades - na história de vida do ser humano, é fundamental levar em consideração que não existe uma adolescência, mas sim adolescências, em função do político, do social, do momento e do contexto em que está inserido o adolescente. Nessa direção, Heilborn (1997), com base em dados de pesquisa realizada com crianças e adolescentes de favelas do Rio de Janeiro, sublinha que o tempo é marcado de forma desigual nas sociedades de classe e que em decorrência dessa desigualdade, a infância e a adolescência passam a ser pensadas e vividas de maneiras distintas.

\section{Material e métodos}

A coleta dos dados foi realizada mediante pesquisa etnográfica, com observação direta, tendo sido desenvolvida por meio da presença da pesquisadora no mesmo espaço por períodos prolongados e em situações/ocasiões diferenciadas, utilizando como técnicas privilegiadas as conversas informais e entrevistas semi-estruturadas. Estas são consideradas importantes pelo fato de nos tornar capazes de apreender o que as próprias pessoas consideram importante, ou que, pelo menos, elas pensam ser importante dizer ao antropólogo (Langness, 1973). Nas conversas informais, temas de grande interesse dos adolescentes como "ficar", namoro, sexualidade, gravidez, maternidade, paternidade foram privilegiados. Esses momentos foram importantes, pois além de terem possibilitado a minha inserção no universo investigado, também permitiram a obtenção de dados referentes aos valores e representações dos adolescentes sobre as suas experiências ligadas a esses temas. Mantive-me atenta nessas ocasiões, não apenas ao que via, mas também ao que ouvia ao meu redor, ou seja, não só ou necessariamente ao grupo que entrevistei. Apesar de a maioria das entrevistas terem sido realizadas no espaço da escola, nos casos em que as adolescentes haviam interrompido os estudos por ocasião do parto, impôs-se a necessidade de as entrevistas se realizarem no local de moradia, momentos em que pessoas da família, sobretudo as mães das mesmas, também tiveram importante participação durante as conversas informais.

O cenário onde vivem os adolescentes é marcado por grande movimento de pessoas nas ruas confirmando a alta densidade demográfica do bairro. Construído por meio de um processo de ocupação intenso, causado, sobretudo pelo grande fluxo imigratório de famílias do interior do Estado do Pará, o bairro do Guamá atualmente é o mais populoso de Belém, com uma população estimada em torno de 98.876 habitantes e um número de domicílios correspondente a 21.046. O mesmo aparece nas estatísticas com a maior incidência de casos de gravidez na adolescência (SEGEP, 1997).

A escola pertence à Rede Pública Estadual de Ensino, atendendo, juntamente com mais quatro, os moradores do bairro. Conta com 2.533 alunos matriculados regularmente, distribuídos em três turnos. A opção por esta escola está ligada às possibilidades que a mesma oferece para a compreensão de um universo em que a gravidez/maternidade é vivenciada/compartilhada pelos adolescentes de maneira específica, o que explica também a opção pelo método qualitativo e não quantitativo de análise. A escolha por um turno, no entanto, prende-se ao fato de no mesmo sobressair uma quantidade maior de adolescentes na faixa etária de 13 a 18 anos, que engravidaram ou tornaram-se mães. No universo de 354 meninas matriculadas nesse turno a incidência de gravidez corresponde a mais de $10 \%$, ou seja, 36 meninas engravidaram durante o ano letivo; destas, 12 permaneceram na escola. Quanto aos demais turnos, um não apresentava à época da pesquisa, nenhuma incidência de gravidez e no outro (noturno) a incidência era mais elevada, porém, as mulheres estavam acima da faixa dos 13 a 18 anos.

A pesquisa foi executada segundo os princípios éticos contidos na Declaração de Helsinki (2000), com observações às suas legislações 
no que diz respeito à questão ética em pesquisa envolvendo seres humanos. O projeto foi submetido e aprovado pelo Comitê de Ética em Pesquisa Envolvendo Seres Humanos da Universidade Federal do Pará (protocolo CEPNMT/ UFPA006/2002).

A investigação contemplou um grupo de 15 estudantes (na faixa de 13 a 18 anos), sendo 12 mulheres e três homens. Considero essa desproporção um dos achados mais surpreendentes da pesquisa, na medida em que levou a um distanciamento das hipóteses iniciais que previam uma relação numérica mais ou menos proporcional entre adolescentes homens e mulheres no âmbito dessa experiência, que se mantiveram na escola. Alguns elementos são sugestivos para uma compreensão desse quadro. Sublinho que, em decorrência da importância da paternidade enquanto símbolo de masculinidade, dentre os parceiros das 12 adolescentes entrevistadas, apenas três se mantém na escola, o que leva a supor que o papel de provedor tende a contribuir para o seu afastamento da mesma. Um outro dado relevante é que, dentre os que abandonaram os estudos, ou seja, a quase totalidade dos parceiros das adolescentes entrevistadas, encontra-se com mais de 19 anos, portanto, um indicativo forte de que a chamada gravidez na adolescência nesse universo tende a ocorrer com maior freqüência entre parceiros não adolescentes.

Dos três adolescentes (parceiros) entrevistados que se mantiveram na escola, dois já haviam tornado-se pais e um aguardava o nascimento do filho. Desses, todos assumiram a paternidade. Quanto às adolescentes, seis estavam grávidas, quatro já haviam tornado-se mães e duas abortaram no início da gravidez. Decidi incluir estas últimas na pesquisa pelo fato de as mesmas possuírem uma trajetória de vida similar a das demais e, sobretudo, pelo desejo manifestado em suas narrativas de tornaremse mães e dar continuidade aos estudos. Vale portanto, o registro das narrativas sobre esses dois casos. Inicialmente fui informada sobre a gravidez de uma delas (13 anos), o que me levou a procurá-la na escola. Durante a conversa, ela revelou-me que havia "tirado" pois temia que seu pai "descobrisse" e a expulsasse de casa. Contou com o apoio da mãe a da irmã “mais velha" ficando esta responsável por "providenciar tudo", enquanto a mãe viajava para o interior do estado, juntamente com o pai, obviamente para que este não desconfiasse de nada. O parceiro não concordou com a decisão, tendo sido esse o motivo da separação do casal. Segundo a mesma, seu "sonho de ser mãe" teve de ser adiado e agora que está trabalhan- do pretende se "amigar" com o atual parceiro para poder realizá-lo.

A outra adolescente (12 anos), é amiga da primeira, tendo sido referida por esta durante a entrevista a respeito da suposta gravidez. Quando a procurei, ela mostrou-se muito feliz com a possibilidade de estar grávida. Depois de dez dias voltei a procurá-la para saber do resultado do teste da gravidez e a encontrei entristecida com o resultado negativo do mesmo. Surpreendi-me com a sua revelação de que continua tentando engravidar, um desejo do qual o parceiro também compartilha. Ficou a dúvida a respeito do aborto, pois no curso das conversas ela revelou que seu pai jamais aceitaria a gravidez fora de uma união, ou seja, sem que ela antes "se amigasse" com o parceiro.

\section{Resultados e discussão}

\section{Das trajetórias afetivo-sexuais}

Compreender os significados sociais da gravidez na adolescência implica focalizar, mesmo que parcialmente, a trajetória afetivo-sexual dos adolescentes. Aqui o "ficar" remete a um código de relacionamento entre os estudantes, sendo utilizado para estabelecer distinções entre experiências sentimentais e/ou sexuais. Em alguns casos, o "ficar” por ser uma relação em que se privilegia o presente, posto que constitui um “envolvimento passageiro", que não pressupõe qualquer tipo de compromisso entre o casal, passa a contrastar com o namorar, que por sua vez configura uma relação marcada por um compromisso pautado por respeito e fidelidade (Rieth, 1998). Em outros, no entanto, sugere uma espécie de "escala” para se alcançar o namoro ou mesmo um compromisso maior, como o “amigar”. Raramente a iniciação sexual, no caso das meninas, ocorre antes do namoro se efetivar, ou seja, durante uma "ficada”. Desse modo, apesar do "ficar" não instaurar um compromisso imediato, expectativas nesse sentido são mantidas pela menina, ao longo das quais os encontros sucedem-se assumindo contornos de "namoro de porta".

Esse aspecto é relevante, pois, das 12 adolescentes entrevistadas, oito delas tiveram a primeira experiência sexual entre 12 e 15 anos, tendo ocorrido no contexto do namoro, um contraste em relação aos três rapazes que tiveram a primeira experiência mais cedo, entre 11 e 13 anos. Cabe ressaltar que o namoro em geral assume caraterísticas tradicionais e obedece a uma hierarquia de gênero na qual cabe à mulher determinar o ritmo e a dinâmica da rela- 
ção. A primeira relação sexual é referida por meninas como um acontecimento marcado por muita insistência dos parceiros, tendo a mesma, por essa razão, se dado em geral, de forma desprotegida. Tal dado aponta uma forte divisão de gênero na cultura sexual desse grupo, comportamento que permanece predominante na cultura sexual brasileira. A primeira experiência sexual tende a se dar de forma desprotegida em razão da persistência dessa definição de papéis de gênero, na qual espera-se da mulher um comportamento passivo e do homem um comportamento ativo (M. Bozon, comunicação pessoal). Nesse sentido, o preparo para uma primeira relação, implicaria a postura ativa por parte da mulher, atitude que poderia passar a idéia de que elas seriam "experientes”, o que por sua vez colocaria dúvidas sobre a sua moralidade. Esse dado sugere existir uma correlação entre a fragilidade da aceitação social da sexualidade juvenil feminina e a fraqueza cada vez maior da aceitação social da contracepção. Remete, portanto, para a lógica da proteção entre o grupo, sobretudo quando se observa que nenhuma das 12 adolescentes afirmou ter o parceiro usado a camisinha como forma de proteção durante a relação, muito embora tenham demonstrado amplo conhecimento da importância de sua utilização.

Sobressai a lógica hierárquica de gênero, pois, sendo a camisinha de domínio masculino, compete ao homem a decisão sobre usá-la ou não. Entre os três parceiros, a mesma foi referida como um obstáculo ao prazer sexual. Por outro lado, tanto as adolescentes quanto os parceiros condicionam o uso do preservativo masculino ao tipo de relacionamento afetivo mantido pelo casal. A expressão "só uso camisinha com as mulheres que não conheço" (Pedro, 16 anos, parceiro de Aline), é emblemática nesse sentido. Assim, quando o relacionamento atinge o estágio do "namoro" ou "namoro firme”, prevalece o não uso da camisinha, atitude que denota valores correspondentes à fidelidade e confiança entre os parceiros. Para os rapazes a fidelidade é mais valorizada do que a virgindade, sendo cobrada da parceira durante a relação. Foram unânimes em afirmar que jamais assumiriam uma relação com "garotas galinhas". Para eles, "garotas galinhas é só para transa" e não para compromisso, pois, "se o cara se recusar, ele é chamado de gay. Aconteceu comigo no colégio, a menina me convidou e eu não quis, ela me chamou de gay e os colegas começaram a me encarnar" (André, 17 anos).

Inseridas as práticas sexuais no contexto do namoro, valores tradicionais sobressaem e se atualizam na tendência por parte das meninas em terem de ceder para que perdure o interesse do parceiro no prosseguimento da relação. Nos relatos das mesmas, a primeira experiência aparece formulada em termos de uma "entrega”, cuja legitimidade ocorre no âmbito de uma relação afetiva já consolidada (o namoro), concretizada a partir da apresentação do parceiro à família, seguida do "pedido" em namoro. É possível pensar então, em uma "representação da virgindade como dádiva" - tal qual proposta por Bozon \& Heilborn (2001) - que é oferecida pela menina ao parceiro com o objetivo de alimentar a troca amorosa. A suposição de que a gravidez também passa por uma representação similar, advém do fato de que alguns marcos temporais ligados a festejos de caráter coletivo, ao lazer e à data de aniversário do namorado/parceiro, foram referidos pelas adolescentes como o momento que marcou a concepção.

\section{A gravidez/maternidade

no cotidiano da escola

A não excepcionalidade da gravidez/maternidade no contexto da escola propicia o amplo debate do tema entre os estudantes. Existe um circuito intenso de informações entre eles - dedutivas ou não - a respeito de quem está ou não grávida. O “não estar grávida” ou "não estar mais grávida”, porém, assume significados distintos dependendo a quem tal afirmação se refere, podendo ser utilizada para definir a situação de uma menina que não estava de fato grávida, tratando-se apenas de uma suspeita do grupo, ou para designar a situação daquela que “esteve, mas não está mais”, sugerindo, neste caso, que a menina praticou aborto, ou como eles próprios referem - "tirou". Especulase desse modo ainda, sobre quem é o provável "pai" e o futuro da relação entre o casal.

As expectativas em torno da gravidez são traduzidas no cotidiano da escola por meio de alguns comportamentos manifestados pelas meninas, sendo estes, em geral, tomados por outras como indicativos de uma suposta gravidez. Há, no entanto, casos em que preferem retrair-se, mantendo-se silenciosas ou mesmo afastando-se, pelo menos num primeiro momento, dos grupos de convívio e sociabilidades construídos na escola. Concorre para o aumento da desconfiança, o fato de as mesmas "encobrirem” mais o próprio corpo, seja usando uma "blusa maior", ou apoiando sempre o caderno ou a bolsa sobre o ventre. Essa mudança de comportamento da menina em relação ao seu próprio corpo se evidencia, pois em geral as mesmas procuram realçar as suas formas usan- 
do microssaias, acompanhadas de miniblusas ou "top", peças que compõem um visual feminino em que costas, colo, ventre e coxas ficam à mostra, regiões do corpo que não escapam aos olhares atentos dos meninos.

Compondo essa rede de relações, nota-se maior afinidade entre as adolescentes grávidas e as que vivenciam a experiência da maternidade, inclusive exercendo estas sobre as demais grande influência e admiração. Em geral, as experiências já vividas por outras em relação à gravidez e maternidade são repassadas para aquelas que se deparam com semelhante situação, dando dicas sobre como conciliar gravidez/maternidade, escola e trabalho. Mas é, contudo, o chá de bebê que expressa com maior nitidez, o caráter positivo da experiência da gravidez/maternidade. Para as professoras, a importância do mesmo é vista com base no aspecto econômico, pois, quase tudo o que é necessário ao bebê, é presenteado pelos participantes nessa ocasião. No entanto, o caráter social do qual se reveste o mesmo, ficou patente tanto na forma coletiva de sua organização, quanto na maneira como todos, indistintamente, compartilharam do mesmo.

\section{O chá de bebê}

O chá de bebê insere-se no conjunto de pequenos eventos comemorativos que são organizados por alunos e professores no espaço da escola, estando o mesmo incorporado ao cotidiano das relações sociais construídas nesse ambiente. Apesar disso, nem sempre é fácil prever quando o mesmo irá acontecer. Assim, apesar de ter sido informada desde o início da pesquisa sobre a freqüência de sua ocorrência, fui alertada para que ficasse atenta, pois segundo os informantes, esse é o tipo de evento que é organizado em sigilo, para que tome forma de surpresa para a menina grávida homenageada pelo grupo.

A festa teve início com a chegada da homenageada, uma estudante de 14 anos, grávida de seis meses que exibia feliz a sua barriga, usando uma minissaia e uma pequena blusa do tipo "top". As demais meninas fascinadas ao tocar sua barriga, faziam comentários elogiosos, tentando adivinhar, pelo formato da mesma, o sexo do bebê. Quando perguntei com quem tinham aprendido a fazer tais distinções, a maioria respondeu que sua mãe ou avó as havia ensinado.

O grupo tecia comentários sobre as outras meninas grávidas da turma (que num total eram três), e sobre as demais da escola. Perguntas eram dirigidas à menina grávida, sobretudo em relação à gravidez e ao seu parceiro. Indagou- se pela reação de sua mãe diante da gravidez, ao que a menina respondeu ter "recebido muito apoio". Perguntou-se ainda, se o futuro pai havia assumido a paternidade; à resposta positiva por parte da menina, seguiu-se outra pergunta: “vocês estão amigados?" Diante da resposta negativa, outra estudante complementou: “o importante é assumir!", sugerindo que, nem sempre a gravidez durante a adolescência instaura uma união, mesmo do tipo consensual (“o amigar-se"), embora seja esse tipo de união usual entre os casais pertencentes às camadas populares em Belém e em outras regiões da Amazônia e do Brasil. O mais importante nesse contexto, é que o parceiro assuma o compromisso (mesmo que seja parcial) em relação ao filho. Vale assinalar ainda que, não "se amigar", nem sempre significa que a relação (namoro) não seja mantida.

Observei ainda que em meio às brincadeiras, meninas maiores pegavam no colo as menores, imitando gestos maternos que sinalizam para a enorme importância que a gravidez/maternidade adquire no universo da escola, o que remete à compreensão de sentidos outros que este espaço assume para o grupo. Contrariando dados que apontam a escola como a grande responsável pela evasão de alunos, seja por meio de problemas entre estes e os professores, seja por preconceitos por parte da instituição (UNICEF, 1993a, apud Madeira, 1997), a escola aqui referida não apresenta tais características, embora alguns aspectos comuns à maioria das escolas sejam-lhes inerentes, como o alto índice de repetência e dos níveis de inadequação série/idade. Assinalo ainda que, apesar da repetência compor esse cenário, não implica a trajetória que leva necessariamente ao abandono da escola. Pelo contrário, pode ser um tipo de estratégia utilizada por muitos alunos para nela permanecerem por um período mais prolongado e manter as redes de sociabilidades construídas nesse ambiente.

Mas a permanência na escola ou a continuidade dos estudos mantém uma correlação com outros fatores. Os projetos profissionais, pensados em termos de mobilidade social futura, foram ressaltados pela maioria das entrevistadas. Do grupo de meninas entrevistadas, apenas uma afirmou não ter planos profissionais para o futuro. A continuidade dos estudos é justificada pelo desejo de entrar na faculdade para obter uma profissão e uma inserção no mercado de trabalho em condições mais favoráveis. A ênfase nos estudos mostrou-se recorrente nas falas das meninas e expressou-se em afirmações do tipo "o estudo é tudo, pois disso depende o meu futuro e o futuro do meu filho" 
(Aline, 14 anos). Assume destaque nesse cenário o fato de, não obstante os adolescentes homens e mulheres exercerem algum tipo de atividade, em geral não as consideram como trabalho, o que aponta para um sentido particular que o trabalho adquire nesse contexto. É importante destacar que o trabalho realizado por elas geralmente assume forma intermitente e flexível, que eles próprios definem como uma “ajuda”. Do mesmo modo, nas conversas com algumas mães, a expressão "ela é o meu braço direito" é ilustrativa de que o trabalho (doméstico), no caso das adolescentes, se impõe desde cedo, inserindo-se no contexto da reprodução do próprio grupo familiar.

\section{Os parceiros}

Muito embora na sociedade brasileira conceber e criar os filhos sejam papéis culturalmente atribuídos às mulheres, os homens, na condição de parceiros das adolescentes assumem papel de relevo nesse contexto (Leal \& Fachel, 1999). Nos relatos dos adolescentes entrevistados, homens e mulheres, essa importância do parceiro aparece relacionada à condição de "provedor", daquele que assume, potencial ou parcialmente a criança, atitude por meio da qual sua identidade passa a ser reafirmada. Durante a entrevista com um dos parceiros das entrevistadas, o mesmo, ao se referir ao não uso da camisinha, sua mãe ressaltou: “...Mas tu não pode ficar fazendo filho porque tu não tem emprego", sugerindo com isso que o termo trabalhar possui significado distinto de ter emprego. Este último em geral encontra-se associado ao fato estarem inseridos regularmente no mercado de trabalho e possuírem uma remuneração mensal fixa, contrastando portanto, com o primeiro, que significa simplesmente encontrarem-se inseridos de forma intermitente (em geral "fazendo bico") em uma atividade qualquer.

Não obstante a expectativa social do papel masculino de provedor impor aos parceiros a responsabilidade material, mesmo que parcial em relação à criança, tal atitude não se estende à garota. Arcar com as responsabilidades de pai e não necessariamente de "pai de família" (já que em apenas cinco casos a gravidez ocasionou a coabitação, originando uma nova família) não minimiza o compromisso do rapaz em relação à criança. Tal dado sugere ainda que, nesse contexto a gravidez nem sempre faz parte de uma "tática" da menina no sentido de acelerar um processo de união (M. Bozon, comunicação pessoal), sem a qual o mesmo se desenrolaria mais lentamente.
De acordo com os relatos das entrevistadas, com exceção de um único caso, todos os parceiros assumiram a paternidade, independentemente da idade e do tipo de vínculo afetivo mantido após o nascimento da criança. Tal aspecto em muito pode iluminar a compreensão da atitude por parte dos demais parceiros das entrevistadas, em abandonar os estudos ao tornarem-se pais, dedicando-se ao trabalho. Embora esse aspecto necessite ser analisado com mais cautela, aponta para a problematização da idade do parceiro como fator que determina/leva em última instância o mesmo a assumir a gravidez, contrariando o argumento do “adolescente não responsável”, que ao deixar de assumir a paternidade, acaba por fazer com que a mãe assuma sozinha a responsabilidade em relação à criança. Entre o universo pesquisado, assumir a paternidade do ponto de vista social e material denota maturidade e responsabilidade, “atitude de macho”. É dessa perspectiva que eles se vêem e são vistos pelo grupo, persistindo um modelo de comportamento em que a lógica tradicional de gênero acaba por limitar as oportunidades para as meninas no âmbito do trabalho, ao tempo em que pode impor aos rapazes situações de grandes constrangimentos no papel de provedores (Heilborn, 1997).

O realce desse ponto é importante, sobretudo porque os parceiros das meninas deste estudo são, em sua maioria, homens com idade acima de 19 anos, portanto não adolescentes. Se por um lado tal aspecto conduz ao questionamento sobre em que medida o fato de ser o parceiro adolescente ou não, implica diferenças significativas nos desdobramentos da gravidez (considerando a expectativa em torno do desempenho por ele do papel de provedor), por outro, instiga uma reflexão futura sobre o que a escolha por um parceiro não adolescente pode significar, do ponto de vista social, para as meninas.

\section{Quando a paternidade não é assumida}

Merece registro o caso de Rita, o único entre o grupo investigado em que a paternidade não foi reconhecida. O contexto de ocorrência de sua gravidez também difere do das demais, tendo a mesma se dado no âmbito de uma relação afetiva que não chegou ao "estágio" de namoro, pois ocorreu durante um "ficar". Interessante também foi a repercussão de seu caso na escola e a mudança das relações com as colegas no mesmo ambiente. Foi nítida a manifestação de surpresa ao saberem que a mesma havia "tido filho" durante o período de férias, pois esse foi 
um caso raro de não ter havido qualquer suspeita da gravidez. Na entrevista, Rita afirmou que manteve silêncio sobre sua gravidez por supor que as colegas não fossem tão receptivas a ela pelo fato de terem conhecimento de que não tinha um "namorado firme", e pelo fato de o ex-parceiro não ter assumido a paternidade. Como contraponto aos demais casos, portanto, este sugere que nesse universo a valorização da gravidez/maternidade pode manter uma estreita ligação com o contexto afetivo em que ela ocorre e, principalmente, com o fato de o parceiro assumir ou não a paternidade.

Maternidade, mudança de status e projeto de mobilidade social

A gravidez/maternidade pode envolver dimensões complexas, o que remete tanto à mudança de status, quanto à reafirmação de projetos de mobilidade social. Nas narrativas das adolescentes esse episódio foi, por diversas vezes, referido como parte de um projeto de vida, uma espécie de "passaporte” para entrar na vida "adulta" e ser reconhecida pela família e por colegas da escola como tal. É fundamentalmente a gravidez/maternidade que propicia a reafirmação dos projetos de ascensão social, atualizando-se no esforço despendido por elas e pela família no sentido da continuidade dos estudos.

Se por um lado as redes de sociabilidade construídas no ambiente da escola estimulam a permanência das adolescentes grávidas/mães na mesma, por outro, a opção pela continuidade dos estudos significa, também, manter firme o projeto de ser alguém na vida, no qual a família assume enorme importância. Há uma nítida tendência entre as adolescentes de não desejar seguir os mesmos ofícios de suas mães (lavadeiras, empregadas domésticas, feirantes etc.) almejando outras possibilidades para o futuro, perspectiva compartilhada pelas mães que acreditam ser, o estudo, o caminho para se alcançar um futuro melhor. A ambigüidade presente na fala de uma entrevistada a esse respeito é reveladora.

“...Depois que tive neném deixei de ser adolescente e agora sou uma mulher adulta, não posso mais sair como antes. Agora que sou mãe tenho mais responsabilidade. Mudou muita coisa na minha vida, mudou pra melhor, sou mais respeitada pela minha família. Agora que tenho ela [a filha], a responsabilidade é muito grande, tudo o que faço é pensando nela. Agora mesmo é que preciso estudar pra poder dar um futuro melhor pra ela...porque sem o estudo a gente não é ninguém" (Raquel, 16 anos).
A importância dos estudos para o projeto de mobilidade social assume lugar de destaque e encontra-se presente na fala das pessoas da família. Na ocasião desta entrevista, enquanto eu ouvia o relato da menina, sua irmã (que é enfermeira), frisou: “tem que estudar! Para não seguir o exemplo dos nossos pais”. A maternidade nesse sentido constitui um reforço ao projeto de ascensão social, pois é a partir dela que os esforços passam a se concentrar na vontade de ser alguém na vida para garantir um futuro melhor aos filhos.

\section{Reflexões finais}

Tomar a gravidez na adolescência no contexto da vida escolar como foco principal nesta análise, conduziu-me a um universo de infinitas possibilidades de significações que envolvem, além das relações afetivo-sexuais das garotas, sobretudo as redes de apoio construídas na escola e na família. Para a maioria das adolescentes entrevistadas, a escolarização constitui parte de um projeto de realização também pessoal, ocupando, junto com a maternidade, um lugar central nas suas vidas. Se, é importante constituir família, esta nem sempre necessita ser reproduzida sob as mesmas condições de vida de suas famílias de origem. Apesar da importância da maternidade nesse contexto, das dificuldades e das poucas alternativas de vida para essas meninas, elas não se mostram dispostas a aceitar tão somente a encenação de papéis de mães e donas-de-casa, embora sejam estes bastante valorizados por elas.

Portanto, ir à escola sem ter vergonha da barriga, trocar experiências com colegas e professores, ser admirada, receber elogios e, sobretudo, ser homenageada com o chá de bebê, compõe os aspectos que marcam o cotidiano dessas meninas na escola, indicativos do valor social que o evento assume nesse universo. Mas o caso de Rita fornece um importante contraponto a esse dado e instiga uma reflexão sobre as regras de aceitação da gravidez entre os estudantes no contexto da escola, o que remete ao questionamento dos valores que podem estar implícitos em atitudes desse tipo. Mais que isso, sugere a importância de se considerar a diversidade de situações em que a gravidez ocorre, não sendo a mesma, apenas indícios do desempenho de uma atividade biológica (Paim, 1998), constituindo eventos também culturais com significados distintos.

Em suma, ainda que nesta análise não tenha sido possível explorar mais detidamente o amplo leque de questões que a riqueza dos da- 
dos da pesquisa aponta, a valorização das experiências dos adolescentes, com ênfase aos episódios que antecederam a gravidez/maternidade, como o ficar/namorar, transar e, sobretudo, a rede de sociabilidade construída na escola, permitiu uma leitura da singularidade do fenômeno para além de uma situação que tem sido, com freqüência, rotulada como homogênea.

\section{Referências}

BOZON, M. \& HEILBORN, M. L., 2001. As carícias e as palavras. Iniciação sexual no Rio de Janeiro e em Paris. Novos Estudos - CEBRAP, 59:11-135.

CAMARANO, A. A., 1998. Fecundidade e anticoncepção da população jovem. In: Jovens Acontecendo na Trilha das Políticas Públicas (Comissão Nacional da População e do Desenvolvimento - CNPD, org.), v. 1, pp. 109-133, Brasília: CNPD.

CARNEIRO, A. B. A. \& MATOS, C. M. A. S., 1999. Gravidez aos 11 anos de idade. Revista Médica de Minas Gerais, 9:119-121.

COSTA, T., 2002. Histórias que Merecem ser Ouvidas e Contadas: Uma Abordagem Antropológica da Gravidez em Adolescentes de 10 a 14 Anos. Dissertação de Mestrado, Rio de Janeiro: Instituto de Medicina Social, Universidade do Estado do Rio de Janeiro.

HEILBORN, M. L., 1997. O traçado da vida: Gênero e idade em dois bairros populares do Rio de Janeiro. In: Quem Mandou Nascer Mulher? Estudos sobre Crianças e Adolescentes no Brasil (F. Madeira, org.), pp. 291-342, Rio de Janeiro: Editora Record/ Rosa dos Tempos.

LANGNESS, L. L., 1973. A História de Vida na Ciência Antropológica. São Paulo: EPU.

LEAL, O. F. \& FACHEL, J., 1999. Jovens, sexualidade e estratégias matrimoniais. In: Sexualidade: O Olhar das Ciências Sociais (M. L. Heilborn, org.), pp. 96116, Rio de Janeiro: Jorge Zahar.

MADEIRA, F., 1997. A trajetória das meninas dos setores populares: Escola, trabalho ou reclusão. In: Quem Mandou Nascer Mulher? Estudos sobre Crianças e Adolescentes no Brasil (F. Madeira, org.), pp. 45-133, Rio de Janeiro: Editora Record/Rosa dos Tempos.
MS (Ministério da Saúde), 1996. PROSAD - Programa Saúde do Adolescente. Bases Programáticas. Brasília: Secretaria Nacional de Programas Especiais de Saúde.

MS (Ministério da Saúde), 1997. Saúde e Desenvolvimento da Juventude Brasileira: Construindo uma Agenda Nacional. Brasília: Secretaria de Políticas Públicas de Saúde.

PAIM, H. S., 1998. Marcas no corpo: Gravidez e maternidade em grupos populares. In: Doenças, Sofrimento, Perturbação: Perspectivas Etnográficas (L. F. Duarte \& O. F. Leal, org.), pp. 31-47, Rio de Janeiro: Editora Fiocruz.

REES, J. M.; LEDERMAN, S. A. \& KIELY, J. L., 1997. Peso de nascimento associado à taxa de mortalidade mais baixa: Filhos de mães adolescentes e adultas. Pediatrics (Edição Brasileira), 1:261-268.

RIETH, F., 1998. Ficar e namorar. In: Horizontes Plurais: Novos Estudos de Gênero no Brasil (C. Bruschini \& H. B. Holanda, org.), pp. 111-134, São Paulo: Fundação Carlos Chagas/Editora 34.

SEGEP (Secretaria Municipal de Coordenação Geral do Planejamento e Gestão), 1997. Anuário Estatístico do Município de Belém. Belém: SEGEP.

STERN, C. \& GARCIA, E., 1999. Hacia un nuevo enfoque en el campo del embarazo adolescente. Reflexiones. Sexualidad, Salud y Reproducción, 13:1-21.

Recebido em 10 de junho de 2003

Versão final reapresentada em 16 de setembro de 2003 Aprovado em 20 de outubro de 2003 